\title{
EFEITO DA DESTOXIFICAÇÃO DO HIDROLISADO DE BAGAÇO DE CANA SOBRE A REMOÇÃO DE FENÓIS, A PERDA DE AÇÚCARES E A BIOCONVERSÃO DE XILOSE EM XILITOL
}

\author{
ARRUDA, Priscila Vaz ${ }^{1}$ \\ CHAUD, Luciana Cristina Silveira ${ }^{2}$ \\ FELIPE, Maria das Graças Almeida ${ }^{3}$ \\ PIVETTA, Lilian Ramos ${ }^{4}$
}

\begin{abstract}
RESUMO: O hidrolisado resultante do processo de hidrólise ácida, metodologia comumente empregada para diferentes materiais lignocelulósicos, contém, além dos açúcares, compostos tóxicos aos microrganismos. Dentre estes, os compostos fenólicos, têm sido mencionados como inibidores da bioconversão de xilose em xilitol, quer pela sua ação individual ou pela interação sinergística entre ele e outros compostos presentes nos hidrolisados como o furfural, hidroximetilfurfural e o ácido acético. Os compostos fenólicos conferem, ainda, ao hidrolisado uma coloração escura, a qual interfere no processo de "downstrean" do xilitol. Este trabalho avaliou dois procedimentos de destoxificação do hidrolisado de bagaço de cana-de-açúcar: ajuste de $\mathrm{pH}$ combinado à adsorção em carvão ativo e floculação por polímero de origem vegetal. Os fenóis totais e as concentrações de xilose e glicose foram determinados pelo método de Folin-Ciocalteu e através de cromatografia líquida, respectivamente. Ambos os tratamentos resultaram em redução da concentração de fenóis totais. Porém, o uso de carvão ativo resultou em maior perda deste composto ( $88.5 \%$ remoção), o que representa $17.8 \%$ de aumento em comparação ao emprego do polímero. A perda de xilose foi mínima (9\%) para ambos os tratamentos empregados. O tratamento de ajuste de $\mathrm{pH}$ combinado à adsorção em carvão ativo foi mais eficiente do que o procedimento de floculação por polímero. Considerando estes ensaios preliminares e também o baixo custo e biodegradabilidade do polímero, pesquisas devem ser realizadas para que se estabeleçam condições mais eficientes do uso deste composto, melhorando a fermentabilidade do hidrolisado e diminuindo a perda de xilose.
\end{abstract}

Palavras-chave: Hidrolisado de bagaço de cana-de-açúcar. Destoxificação. Xilitol. Xilose. Compostos fenólicos.

SUMMARY: The hydrolysate resulting from the acid hydrolysis process, a method usually employed for different lignocellulosic materials, contains, besides sugars, compounds that are toxic to the microorganisms. Among them, there are the phenolic compounds, that have inhibitory effect on the xylose-to-xylitol bioconversion, due to their individual action and also to their synergistic interaction with other compounds present in the hydrolysates, such as furfural, hydroxymethylfurfural and acetic acid. Furthermore, the phenolic compounds are responsible for the dark color of the hydrolysate, which interferes in the xilitol downstream process. This work evaluated two procedures of sugarcane bagasse hydrolysate detoxification: $\mathrm{pH}$ adjusting with active charcoal adsorption, and a vegetable-origin polymer flocculation technique. The total phenolics and the xylose and glycose concentrations were determined by Folin-Ciocalteu method and liquid chromatography, respectively. Both treatments resulted in reduction of total phenolics concentration. However, the use of active charcoal resulted in higher loss of this compound ( $88.5 \%$ removal), that represents $17.8 \%$ increase when comparised to the use of polymer. The xylose loss was minimum ( $8 \%$ ) for both used treatments. The treatment using the combination of $\mathrm{pH}$ adjustment and active charcoal adsorption was more efficient than the procedure that used vegetable-origin polymer. Considering these preliminary assays and also the polymer low cost and its biodegradability, researches must be performed in order to establish conditions for the most effective use of this compound, improving the hydrolysate fermentability

1 Doutoranda/CAPES, DEBIQ, EEL-USP. Estrada Municipal do Campinho s/n, CEP 12602-810, LorenaSP. e-mail: priscilavaz_eb@yahoo.com.br

2 Mestranda, DEBIQ, EEL-USP. Estrada Municipal do Campinho s/n, CEP 12602-810, Lorena-SP. e-mail: lu_chaud@yahoo.com.br

3 Professora orientadora, DEBIQ, EEL-USP. Estrada Municipal do Campinho s/n, CEP 12602-810, Lorena-SP. e-mail: mgafelipe@eel.usp.br

4 Iniciação Científica/CNPq-PIBIC, DEBIQ, EEL-USP. Estrada Municipal do Campinho s/n, CEP 12602810, Lorena-SP. e-mail: licapivetta@gmail.com 
and decreasing the xylose loss.

Keywords: Sugarcane bagasse hydrolysate. Detoxification. Xylitol. Xylose. Phenolic compounds.

\section{INTRODUÇÃO}

O Brasil é o maior produtor de cana-de-açúcar do mundo, tendo sido estimada uma produção de 475,07 milhões de toneladas para a safra 2007/2008, superior em 10,62\% à safra de 2006/2007 (CONAB, 2007). Considerando que cada tonelada de cana processada tem o potencial de gerar $280 \mathrm{~kg}$ de bagaço, e que seu aproveitamento nos setores sucroalcooleiros para geração de energia fica em torno de 70 e 90\% (ABRABI, 2005), o excedente de bagaço, ainda, é enorme o que tem impulsionado as pesquisas na busca de alternativas de seu aproveitamento.

Em termos de composição, o bagaço de cana é constituído por três frações principais (celulose, hemicelulose e lignina) que, juntas, perfazem mais de $90 \%$ da massa total. A elevada concentração de xilose na fração hemicelulósica do bagaço, o que corresponde em até $80 \%$ do total de açúcar nesta fração (RODRIGUES et al., 2001) e a capacidade de sua assimilação por várias leveduras (FELIPE, 2004) impulsionam as pesquisas para seu aproveitamento em diferentes processos de bioconversão, e para a produção de xilitol. Entretanto, para este bioprocesso, é necessária a liberação de seus açúcares da fração hemicelulósica por procedimentos de hidrólise como a hidrólise alcalina, a enzimática e a ácida, sendo que esta última tem sido a mais empregada nas pesquisas biotecnológicas de obtenção de xilitol a partir de diferentes materiais lignocelulósicos (FELIPE, 2004). Há de se destacar que, durante a hidrólise ácida, na qual se utiliza alta pressão e temperatura (ROBERTO et al., 2003), além dos açúcares de interesse, são gerados vários subprodutos os quais podem ser divididos em três grandes grupos de acordo com a sua origem: derivados do furano (furfural e hidroximetilfurfural), derivados da lignina (compostos fenólicos) e ácidos fracos (acético, fórmico e levulínico) (PALMQVIST; HAHN-HÄGERDAL, 2000). Segundo Rodrigues et al. (2001), cátions como ferro, cromo e níquel estão também presentes no hidrolisado hemicelulósico de bagaço de cana obtido por hidrólise ácida. O reator de aço inoxidável utilizado no processo de hidrólise é uma fonte em potencial de liberação destes cátions durante o preparo do hidrolisado (WATSON et al., 1984).

Os subprodutos gerados durante o processo de hidrólise do bagaço afetam negativamente o metabolismo microbiano, prejudicando a conversão dos açúcares nos produtos de interesse (PALMQVIST; HAHN-HÄGERDAL, 2000; RODRIGUES et al., 2001; FELIPE, 2004; MARTON et al., 2006). Por outro lado, segundo Silva; Matos; Carvalho (2005), a hidrólise ácida poderá ser vantajosa e minimizar a formação de produtos de degradação, desde que as condições de hidrólise (temperatura, tempo de residência e concentração de ácido) sejam otimizadas.

Pesquisas relacionadas aos efeitos inibitórios da atividade microbiana, causados em 
função da presença nos hidrolisados hemicelulósicos de compostos tóxicos aos microrganismos, revelam que tais efeitos dependem não só do tipo e concentração dos compostos, mas também da atuação sinergística entre eles (FELIPE, 2004). No caso dos compostos fenólicos, os quais exercem efeito inibitório considerável nas fermentações de hidrolisados hemicelulósicos, a ação destes está relacionada à perda da integridade da membrana biológica com conseqüente prejuízo no seu papel de barreira seletiva e matrizes enzimáticas, observando-se a diminuição da inibição da fermentação quando monômeros de ácidos fenólicos são, significantemente, removidos do hidrolisado (PALMQVIST; HAHN-HÄGERDAL, 2000). Felipe et al. (1999), avaliando o efeito tóxico do fenol na fermentação de meio semi-sintético por Candida guilliermondii, constataram que a presença de baixa concentração $(0,05 \mathrm{~g} / \mathrm{L})$ deste composto no meio foi suficiente para inibir, drasticamente, a assimilação de xilose por esta levedura com danos à morfologia celular. Segundo estes autores, provavelmente ocorreu inibição da atividade da xilose redutase, enzima chave no passo inicial de assimilação de xilose, ou do transporte de xilose através da membrana plasmática, já que a assimilação desta pentose foi, também, drasticamente afetada.

Em função da presença nos hidrolisados hemicelulósicos, de compostos tóxicos aos microrganismos, diferentes métodos químicos, físicos e biológicos têm sido empregados para a remoção destes de forma a favorecer a fermentabilidade dos hidrolisados como a alteração de pH, por meio da adição de ácidos e bases (ROBERTO et al., 1991), a combinação da alteração de pH e adsorção em carvão vegetal ativado (ALVES et al., 1998; MARTON, 2002), a combinação da adsorção em carvão vegetal e resinas de troca iônica (CARVALHO JUNIOR; MARTON; FELIPE, 2005) e a floculação por polímeros vegetais (SILVA et al, 2006).

Roberto et al. (1991) avaliaram a destoxificação do hidrolisado hemicelulósico de bagaço de cana, obtido por "steam explosion", pelo método de alteração do $\mathrm{pH}$, o qual consistiu na elevação deste por meio da adição ao hidrolisado de um álcali, seguida da sua redução com ácido e verificaram a melhoria da fermentabilidade do hidrolisado após este procedimento. Segundo estes autores, o tratamento empregado proporcionou a remoção de compostos fenólicos que foi favorecida pela presença de íons cálcio devido à base utilizada no tratamento. Comportamento semelhante foi encontrado por Alves et al. (1998), avaliando a metodologia de alteração de pH combinada à adsorção em carvão vegetal, na destoxificação do hidrolisado hemicelulósico de bagaço de cana, porém, obtido por hidrólise ácida. Esses autores atribuíram aos íons cálcio presente no meio, a capacidade de perda de compostos tóxicos aos microrganismos, ocorrida durante a etapa de precipitação, após o ajuste de $\mathrm{pH}$ do hidrolisado com óxido de cálcio. Para Martinez et al. (2001), o tratamento pela alteração de pH contribuiu para a precipitação de compostos aromáticos e para a conversão de furfural em álcool furfurílico, enquanto Amartey e Jefries (1996) relataram que os açúcares podem ser também degradados durante este processo.

Marton (2002), ao avaliar a destoxificação do hidrolisado hemicelulósico de bagaço de cana, também obtido por hidrólise ácida, pela metodologia de alteração de $\mathrm{pH}$ combinada à adsorção em carvão vegetal ativado, constatou que este procedimento reduziu a concentração de compostos fenólicos, porém propiciou a remoção, também, de xilose. Segundo o mesmo 
autor, a condição de maior remoção de compostos tóxicos não coincidiu com a de maior fermentabilidade do hidrolisado. Foi estabelecido neste trabalho, como a melhor condição para a destoxificação de hidrolisado de bagaço de cana, a combinação do ajuste de $\mathrm{pH}$ do hidrolisado pela sua elevação para 7,0, com óxido de cálcio e redução para pH 2,5, com ácido fosfórico seguida da adsorção em carvão vegetal ativado (1\%p/v), sob agitação de $100 \mathrm{rpm}$, a $60^{\circ} \mathrm{C}$ durante 30 minutos. Nestas condições de tratamento, foi obtida a redução de $76 \%$ de fenóis, porém, perda de $22 \%$ de xilose.

A utilização de resinas de troca iônica também tem sido empregada para o tratamento de hidrolisados hemicelulósicos, e seu mecanismo de atuação deve-se à capacidade destas de adsorver diversos subprodutos do hidrolisado, e também de clarificação do mesmo (CANILHA et al., 2004; MARTON, 2005). Em trabalho realizado por Carvalho Junior; Marton; Felipe (2005) ,no qual se utilizou a combinação de resinas e carvão, verificou-se a eficácia deste procedimento na remoção de $95 \%$ de fenóis com conseqüente melhoria da fermentabilidade do hidrolisado de bagaço, porém ocorreu perda de 40\% de D-xilose, o que é indesejável; além do fato das resinas serem caras e exigirem extensivas etapas de regeneração. Segundo os mesmos autores, tratamento com resinas e carvão é mais eficaz para a remoção de fenóis do hidrolisado de bagaço de cana em comparação à utilização de metodologia de alteração de $\mathrm{pH}$ combinada à adsorção em carvão vegetal ativado.

$\mathrm{Na}$ busca de métodos mais eficientes e de baixo custo para o tratamento do hidrolisado hemicelulósico de bagaço de cana, pesquisas se iniciaram com a utilização de polímeros vegetais (SILVA, 2006). Os polímeros à base de tanino vegetal podem ser empregados como um tratamento alternativo, a fim de remover compostos tóxicos do hidrolisado hemicelulósico, uma vez que estes polímeros possuem capacidade de se ligarem às proteínas, insolubilizando-as, além de formarem complexos com metais e removerem fenóis de efluentes e águas, bem como de serem biodegradáveis, de baixo custo e de fácil manipulação (ACQUAQUÍMICA, 2008 a e b). Em trabalhos recentes, utilizando estes polímeros para a destoxificação do hidrolisado hemicelulósico de bagaço de cana, obtido da moagem artesanal durante preparo de caldo de cana, foi constatada a capacidade destes de removerem valores superiores a $80 \%$ de compostos fenólicos e íons metálicos, sem perda significativa de xilose (SILVA, 2006).

Uma vez que estes procedimentos de destoxificação vêm sendo realizados como metodologias isoladas, e os hidrolisados de bagaço de cana empregados apresentam variações nas concentrações de açúcares e de compostos tóxicos, a avaliação simultânea destes procedimentos em um único hidrolisado poderá assegurar uma análise mais precisa dos resultados, de forma a se obter uma metodologia eficaz para contornar o problema da toxicidade destes compostos aos microrganismos e melhorar a fermentabilidade dos hidrolisados para que estes possam ser eficientemente empregados em processos de bioconversão como para a produção de xilitol.

A importância das pesquisas sobre xilitol se deve às suas propriedades peculiares, as quais permitem sua crescente aplicação em diversos segmentos industriais. Este produto é um álcool pentahidroxilado $\left(\mathrm{C}_{5} \mathrm{H}_{12} \mathrm{O}_{5}\right)$, obtido comercialmente por processo químico (Patente 
\# 4.008.285) a partir de materiais lignocelulósicos ricos em xilana (polímero de D-xilose) (MELAJA; HÄMÄLÄINEN, 1977). Este tem sido empregado nas indústrias alimentícia, farmacêutica e odontológica em diferentes países (CCC, 2007), enquanto, no Brasil, a sua utilização está voltada, principalmente, para produtos como creme dental, gomas de mascar e pastilhas. Na Ásia, atualmente, cerca de 80 a 90\% das gomas de mascar vendidas têm xilitol nas suas formulações (CCC, 2007). A ampla aplicação do xilitol se deve às suas características importantes como poder adoçante semelhante ao da sacarose e superior ao de polióis comuns, além de valor calórico reduzido (HYVÖNEN; KOIVISTOINEN; VOIROL, 1982). Aliada a estas propriedades, merece destaque a sua não cariogenicidade, uma vez que este não é assimilado pelos microrganismos da flora bucal, além deste promover a remineralização dos dentes, revertendo lesões recém formadas (SHEN et al., 2001).

Uma outra característica importante do xilitol é o seu metabolismo independente da insulina, tornando-o um substituto de outros açúcares na dieta de diabéticos (PEPPER; OLINGER, 1988). Este adoçante também pode ser empregado no tratamento de outras desordens metabólicas, como a deficiência da enzima glicose-6-fosfato desidrogenasse e a obesidade, uma vez que a ingestão de alimentos contendo xilitol contribui muito pouco para a formação de tecidos gordurosos quando comparado a outros açúcares (MANZ et al., 1973).

Outra aplicação clínica do xilitol, constatada em pesquisas com ratos, é a sua utilização na prevenção de osteoporose, pela sua capacidade de impedir a progressão desta doença pelo aumento da massa óssea e propriedades biomecânicas dos ossos (MATTILA, KNUUTTILA; SVANBERG, 1998). Pesquisas também comprovaram a sua eficácia no tratamento de doenças respiratórias, como a fibrose cística, uma doença que afeta, principalmente, os pulmões e o sistema digestivo (ZABNER et al., 2000). Estes autores constataram, em testes com humanos, que o uso inalatório do xilitol em "spray" resultou na diminuição da concentração salina da camada superficial da membrana respiratória, o que favoreceu a imunidade própria desta superfície e, como conseqüência, reduziu o número de bactérias do gênero Staphylococcus coagulase-negativa na cavidade nasal de voluntários, diminuindo o risco de infecções bacterianas pulmonares.

Em função das importantes propriedades do xilitol, o qual pode ser obtido da fermentação de hidrolisados hemicelulósicos ricos em xilose e devido à presença nestes de compostos tóxicos aos microrganismos, este trabalho busca avaliar, comparativamente, metodologias de destoxificação do hidrolisado hemicelulósico de bagaço de cana-de-açúcar, de forma a contribuir para o estabelecimento de um procedimento eficaz de destoxificação que permita a máxima remoção de fenólicos e mínima perda de xilose com conseqüente melhoria da bioconversão de xilose em xilitol pela levedura Candida guilliermondii. 


\section{MATERIAL E MÉTODOS}

\subsection{OBTENÇÃO E CONCENTRAÇÃO DO HIDROLISADO HEMICELULÓSICO DO BAGAÇO DE CANA}

O hidrolisado foi obtido por hidrólise ácida do bagaço (proveniente da Usina Guarani, Olímpia-SP), na planta piloto do Departamento de Engenharia Química (DEQUI) da Escola de Engenharia de Lorena-USP. A hidrólise ocorreu em reator de aço inox AISI 316 com capacidade total de 350 litros, segundo condições previamente estabelecidas: temperatura de $121^{\circ} \mathrm{C}$, por 10 minutos, empregando $100 \mathrm{mg}$ de $\mathrm{H}_{2} \mathrm{SO}_{4}$ concentrado por $1 \mathrm{~g}$ de matéria seca e uma relação final matéria seca - solução ácida de 1:10 (MARTON et al., 2006).

Após a hidrólise, o hidrolisado foi, primeiramente, concentrado a vácuo em concentrador de aço inoxidável a $70^{\circ} \mathrm{C}$, visando a elevar o teor inicial de xilose em função de que o aumento da concentração inicial desta pentose favorece a produção de xilitol por Candida guilliermondii (FELIPE et al., 1997), além de propiciar, também, a remoção parcial de compostos tóxicos voláteis ( RODRIGUES et al., 2001). Após este procedimento, o hidrolisado foi, então, submetido aos diferentes métodos de destoxificação.

\subsection{PROCEDIMENTOS DE DESTOXIFICAÇÃO DO HIDROLISADO}

O hidrolisado, após sua concentração e determinação de açúcares e fenóis totais, foi submetido aos procedimentos abaixo:

- Alteração de pH e adsorção em carvão vegetal ativado

$\mathrm{O}$ procedimento realizado consistiu na alteração do $\mathrm{pH}$ do hidrolisado, combinado à adsorção em carvão vegetal ativado (Carbonato delta-A), produzido pela BRASILAC. A alteração do $\mathrm{pH}$ ocorreu por adição ao hidrolisado $(\mathrm{pH} 0,8)$ de óxido de cálcio comercial $(\mathrm{CaO})$ até $\mathrm{pH} 7,0$, seguido da redução para 2,5, com ácido fosfórico $\left(\mathrm{H}_{3} \mathrm{PO}_{4}\right)$. Após esta etapa, o hidrolisado foi misturado ao carvão (1\%) sob agitação em incubadora de movimento rotatório (New Brunswick, Scientific Co.) a $100 \mathrm{rpm}$, a $60^{\circ} \mathrm{C}$, durante 30 minutos. Ao final de cada etapa de tratamento (alteração de $\mathrm{pH}$ e adsorção com carvão), o precipitado resultante foi removido por filtração a vácuo, para remoção do precipitado formado (MARTON et al., 2006).

- Floculação por polímero de origem vegetal

$\mathrm{O}$ hidrolisado teve seu pH inicial $(0,8)$ ajustado para $\mathrm{pH} 8,0$ com $\mathrm{CaO}$, e, após filtração, para remoção do precipitado formado, foi deixado em contato com polímero Acquapol $(5 \% \mathrm{v} /$ v), comercializado pela Acquaquimica (ACQUAQUÍMICA, 2008 a), em frascos Erlenmeyer de $125 \mathrm{~mL}$, sob agitação de $200 \mathrm{rpm}$ a $25^{\circ} \mathrm{C}$ por $45 \mathrm{~min}$. Para a remoção do precipitado formado, o hidrolisado foi centrifugado a $4000 \mathrm{rpm}$ por $10 \mathrm{~min}$, conforme metodologia estabelecida por Silva (2006).

Após a verificação da eficácia dos métodos de destoxificação feita a partir da avaliação 
da redução da concentração dos fenóis, bem como da perda de açúcares e da clarificação do hidrolisado, estes foram empregados para as fermentações.

\subsection{MEIO E CONDIÇÕES DE FERMENTAÇÃO}

- Microrganismo e preparo do inóculo

Os experimentos foram realizados com a levedura Candida guilliermondii FTI 20037, sendo o inóculo obtido a partir do cultivo desta levedura em meio contendo xilose $(30 \mathrm{~g} / \mathrm{L})$, $\left(\mathrm{NH}_{4}\right)_{2} \mathrm{SO}_{4}(2 \mathrm{~g} / \mathrm{L}), \mathrm{CaCl}_{2} \cdot 2 \mathrm{H}_{2} \mathrm{O}(0,1 \mathrm{~g} / \mathrm{L})$ e extrato de farelo de arroz $(20 \mathrm{~g} / \mathrm{L})$. O cultivo foi feito em frascos Erlenmeyer de $(125 \mathrm{~mL})$, contendo $50 \mathrm{~mL}$ do meio em incubadora de movimento rotatório (New Brunswick, Scientific Co.) com agitação de $200 \mathrm{rpm}$, a $30^{\circ} \mathrm{C}$ por 24 horas. Após este período, as células foram recuperadas por centrifugação a 2000 x g, lavadas com água destilada esterilizada, sob nova centrifugação. O sobrenadante foi descartado e a massa celular foi empregada para obtenção de uma suspensão em água esterilizada, a qual foi utilizada como inóculo. A concentração inicial de células em cada frasco Erlenmeyer correspondeu a 1,0 g/L de células, em função de esta ter sido a considerada como favorável a esta bioconversão, de acordo com estudos de Felipe et al. (1997).

- Condições de fermentação

As fermentações foram realizadas em meio formulado com os hidrolisados tratados sob as condições estabelecidas, suplementados com os mesmos nutrientes empregados para o preparo do inóculo, exceto a xilose. Para todas as condições avaliadas, o pH inicial de fermentação foi 5,5 e, quando necessário, este foi corrigido com solução de $\mathrm{NaOH}-3 \mathrm{~N}$, durante o preparo do meio. As fermentações foram realizadas em frascos Erlenmeyer $(125 \mathrm{~mL})$ em triplicata, com 50 $\mathrm{mL}$ dos meios, a $30^{\circ} \mathrm{C}$, sob agitação de $200 \mathrm{rpm}$ em incubadora de movimento rotatório (New Brunswick, Scientific Co.), por 66 horas.

A performance fermentativa foi avaliada a partir da determinação do consumo de açúcares e da formação de xilitol.

\subsection{MÉTODOS ANALÍTICOS}

- Determinação da concentração de açúcares e xilitol

As concentrações dos açúcares glicose e xilose, bem como de xilitol foram determinadas por Cromatografia Liquida de Alta Eficiência (HPLC) nas seguintes condições previamente estabelecidas: coluna "Bio-Rad Aminex" HPX-87H mantida a $45{ }^{\circ} \mathrm{C}$; detector de índice de refração RID 6A; eluente ácido sulfúrico $0,01 \mathrm{~N}$, fluxo de 0,6 mL/min.; volume da amostra injetada, $20 \mu \mathrm{L}$. As amostras foram, previamente, diluídas e filtradas em filtro "Sep Pack" C18 (MILLIPORE) (RODRIGUES et al., 2006).

- Determinação da concentração de fenóis totais

A concentração de fenóis totais foi determinada, utilizando-se o método de Folin- 
Ciocalteu, descrito por Singlenton, Orthofer e Lamuela-Raventós (1999). Primeiramente, foram preparados $3 \mathrm{~mL}$ de amostra do hidrolisado diluído e adicionados a este 0,2 $\mathrm{mL}$ de reagente de Folin. Passados 3 a 5 minutos, adicionou-se $0,8 \mathrm{~mL}$ de solução de carbonato de sódio $(150 \mathrm{~g} / \mathrm{L})$. Os tubos foram agitados em vórtex e mantidos no escuro. Decorridos 30 minutos, a absorvância da solução resultante foi lida a $760 \mathrm{~nm}$ em espectrofotômetro computadorizado BECKMAN DU 640 B e comparada a uma curva de calibração em que se utilizou vanilina, como padrão.

\subsection{DETERMINAÇÃO DOS PARÂMETROS FERMENTATIVOS}

- Fator de Rendimento de D-xilose em Xilitol ( $Y_{P / S)}$

$\mathrm{O}$ fator de rendimento foi calculado pela equação 1 :

$$
\begin{gathered}
\mathrm{Y}_{\mathrm{P} / \mathrm{S}}=\underline{\Delta \mathrm{P}}=\underline{\mathrm{P}}_{\mathrm{f}}-\mathrm{P}_{\mathrm{i}-} \\
\Delta \mathrm{S} \quad \mathrm{S}_{\mathrm{f}}-\mathrm{S}_{\mathrm{i}}
\end{gathered}
$$

Em que:

$\mathrm{S}_{\mathrm{i}}$ e $\mathrm{S}_{\mathrm{f}}$ correspondem às concentrações inicial e final de xilose $(\mathrm{g} / \mathrm{L})$;

$\mathrm{P}_{\mathrm{i}}$ e $\mathrm{P}_{\mathrm{f}}$ correspondem às concentrações inicial e final de xilitol $(\mathrm{g} / \mathrm{L})$.

- Produtividade Volumétrica de Xilitol $\left(Q_{p}\right)$

A produtividade volumétrica de xilitol foi calculada de acordo com a equação 2 :

$$
\begin{gathered}
\mathrm{Q}_{\mathrm{p}}=\underline{\Delta \mathrm{P}}=\underline{\mathrm{P}}_{\mathrm{f}}-\mathrm{P}_{\mathrm{i}} \\
\Delta \mathrm{T} \quad \mathrm{T}_{\mathrm{f}}-\mathrm{T}_{\mathrm{i}}
\end{gathered}
$$

Em que:

$\mathrm{P}_{\mathrm{i}}$ e $\mathrm{P}_{\mathrm{f}}$ correspondem às concentrações inicial e final de xilitol $(\mathrm{g} / \mathrm{L})$;

$\mathrm{T}_{\mathrm{i}}$ e $\mathrm{T}_{\mathrm{f}}$ correspondem aos tempos inicial e final de fermentação $(\mathrm{h})$.

\section{RESULTADOS E DISCUSSÃO}

As concentrações dos açúcares glicose e xilose, bem como de fenólicos presentes no hidrolisado hemicelulósico de bagaço de cana não tratado (A), assim como posterior aos tratamentos, como a alteração de pH combinado à adsorção em carvão vegetal ativado (B) e floculação por polímero vegetal (C), estão apresentadas na Tabela 1. Observa-se nesta Tabela que o hidrolisado continha predominância da pentose (xilose) em relação à hexose (glicose). A predominância de xilose no hidrolisado hemicelulósico de bagaço de cana é imprescindível, uma vez que esta pentose, substrato para a obtenção de xilitol, influencia este bioprocesso, em função de sua concentração no meio (ROSA et al., 1998; FELIPE et al., 1997). Quanto 
à glicose, relatada como responsável por exercer a repressão catabólica do metabolismo de xilose (BICHO et al. 1988; SUGAI; DELGENES, 1995), foi encontrada como benéfica a este bioprocesso nas fermentações do hidrolisado de bagaço de cana, na proporção glicose:xilose igual a 1:5 (SILVA; FELIPE, 2006). Verifica-se, ainda, nesta Tabela, a presença de elevada concentração de fenóis no hidrolisado $(9,60 \mathrm{~g} / \mathrm{L})$, compostos resultantes do procedimento de hidrólise ácida do bagaço e considerados tóxicos aos microrganismos devido à interferência nas membranas celulares (PALMQVIST; HAHN-HÄGERDAL, 2000).

Tabela 1: Concentração de açúcares e fenóis totais dos hidrolisados de bagaço de cana obtidos por hidrólise ácida anterior aos métodos de destoxificação (A); após tratamento combinando alteração de $\mathrm{pH}$ e adsorção em carvão vegetal ativado (B) e após tratamento com polímero de origem vegetal (C).

\begin{tabular}{ccccc}
\hline \multicolumn{2}{c}{$\begin{array}{c}\text { Componentes } \\
\text { do hidrolisado }(\mathbf{g} / \mathbf{L})\end{array}$} & $\begin{array}{c}\text { Sem } \\
\text { tratamento } \\
(\mathbf{A})\end{array}$ & $\begin{array}{c}\text { Tratamento } \\
(\mathbf{B})\end{array}$ & $\begin{array}{c}\text { Tratamento } \\
(\mathbf{C})\end{array}$ \\
\hline \multirow{2}{*}{ Açúcares } & Glicose & 2,35 & 0,77 & 1,07 \\
& Xilose & 58,48 & 53,80 & 53,35 \\
\hline $\begin{array}{c}\text { Compostos } \\
\text { tóxicos }\end{array}$ & Fenóis & 9,60 & 1,11 & 2,62 \\
\hline
\end{tabular}

O efeito dos tratamentos do hidrolisado sobre a remoção de fenóis totais e dos açúcares pode ser constatado na Tabela 1 e Figura 1, encontrando-se que ambos os procedimentos proporcionaram a remoção de fenóis, tornando-o um meio de cultivo mais favorável ao crescimento de microrganismos. Nota-se na Figura 1, que o tratamento pela alteração de $\mathrm{pH}$ combinado à adsorção em carvão ativo (B), foi melhor método de destoxificação por reduzir $88,5 \%$ de fenóis, valor superior em $17,8 \%$ em relação ao tratamento no qual se empregou polímero vegetal (C). A concentração de fenóis encontrada no hidrolisado, após os tratamentos, é considerada elevada e inibitória do metabolismo de xilose por C. guilliermondii, uma vez que Felipe et al. (1999) constataram que a presença de apenas $0,05 \mathrm{~g} / \mathrm{L}$ deste composto no meio semi-sintético, contendo $40 \mathrm{~g} / \mathrm{L}$ de xilose como fonte de carbono, foi suficiente para inibir, drasticamente, a assimilação deste açúcar e crescimento da levedura. Verifica-se, ainda, nesta Figura, que ambos os procedimentos resultaram na perda de açúcares, sendo a maior perda observada para a glicose $(67,2 \%)$, quando se utilizou a alteração de $\mathrm{pH}$ combinada à adsorção em carvão vegetal ativado (B), enquanto, quando se empregou o polímero (C), esta perda foi de 54,5\%. Com relação à xilose, verifica-se menor perda comparada à glicose, sendo esta semelhante para ambos os tratamentos (aproximadamente 9\%). De acordo com os resultados, a combinação do tratamento pela alteração do $\mathrm{pH}$ e adsorção em carvão vegetal ativado propiciou a máxima remoção de fenóis e a mínima perda de açúcares. Carvalho, Marton e Felipe (2005) também constataram a eficácia do tratamento pela alteração de $\mathrm{pH}$ e adsorção em carvão vegetal ativado sobre a remoção de fenóis do hidrolisado hemicelulósico de bagaço de cana obtido por hidrólise ácida, cujos valores foram semelhantes aos obtidos no presente trabalho, porém, a 
perda de xilose foi superior, alcançando valores próximos a $20 \%$.

Silva (2006), avaliando a utilização de polímero vegetal para a destoxificaçao do hidrolisado hemicelulósico de bagaço de cana, porém obtido da moagem artesanal durante preparo de caldo de cana, encontrou remoção de $75,47 \%$ de compostos fenólicos totais e perda mínima de xilose (aproximadamente 7\%), valores muito semelhantes ao encontrado no presente trabalho (Figura 1).

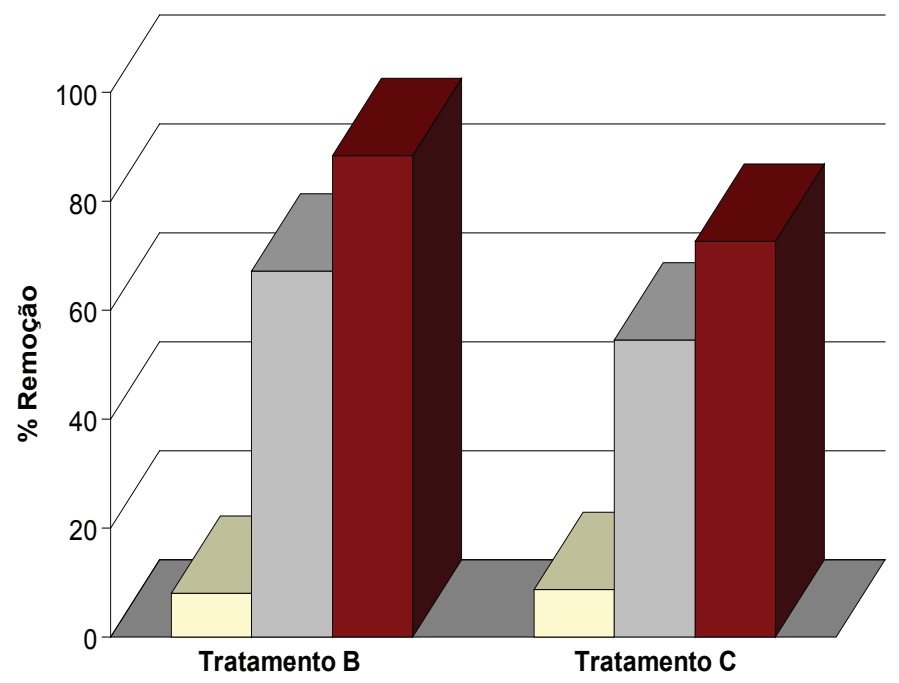

Figura 1: Remoção (\%) de xilose ( $\square$ ), glicose ( $\square$ ) e fenóis totais ( $\square$ ) do hidrolisado hemicelulósico de bagaço de cana após a destoxificação pela alteração de $\mathrm{pH}$ combinado à adsorção em carvão vegetal ativado (B) e floculação por polímero vegetal (C).

O efeito dos procedimentos de destoxificação foi ainda verificado sobre a remoção de cor do hidrolisado (Figura 2). Verifica-se que, quanto maior o teor de fenóis, mais intensa é a sua coloração, conforme pode ser verificado nas Figuras 1 e 2. Segundo Marton (2002) e Viñals (2001), a coloração do hidrolisado está relacionada à presença de fenólicos. Segundo Martinez (2005), a coloração do caldo fermentado contendo xilitol é um aspecto importante na recuperação deste pelo processo de cristalização. De acordo com o mesmo autor, esta etapa é uma das mais difíceis do processo fermentativo em si, devido à baixa concentração do produto formado e a composição complexa do caldo fermentado obtido. 


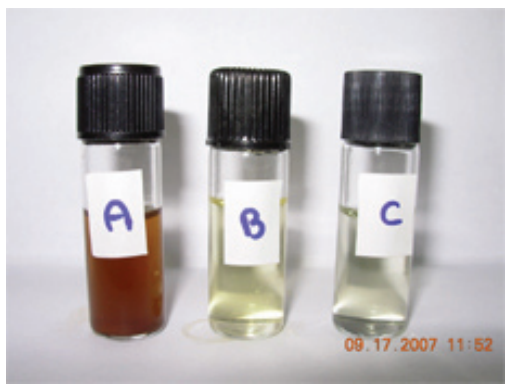

Figura 2: Hidrolisado hemicelulósico de bagaço de cana obtido por hidrólise ácida anterior (A) e posterior à destoxificação pelos métodos de alteração de $\mathrm{pH}$ combinado à adsorção em carvão vegetal ativado (B) e floculação por polímero vegetal (C).

O efeito dos diferentes tratamentos do hidrolisado pode ser também constatado sobre a bioconversão de xilose em xilitol pela levedura (Figuras 3 e 4). Verifica-se, na Figura 3, que o consumo de xilose foi influenciado pelo tipo de tratamento, uma vez que a alteração de $\mathrm{pH}$, combinado à adsorção em carvão vegetal ativado (B), propiciou o consumo de $99 \%$ de xilose, enquanto $88 \%$ desta pentose foi consumida com a utilização do polímero (C). Esta condição de maior consumo de xilose (Figura 3), que correspondeu à de maior redução de fenóis (Figura 1), resultou em favorecimento da formação de xilitol (Figura 3), sendo a máxima concentração de $22,3 \mathrm{~g} / \mathrm{L}$, o que correspondeu a um aumento de $24,3 \%$ em relação à utilização do polímero.

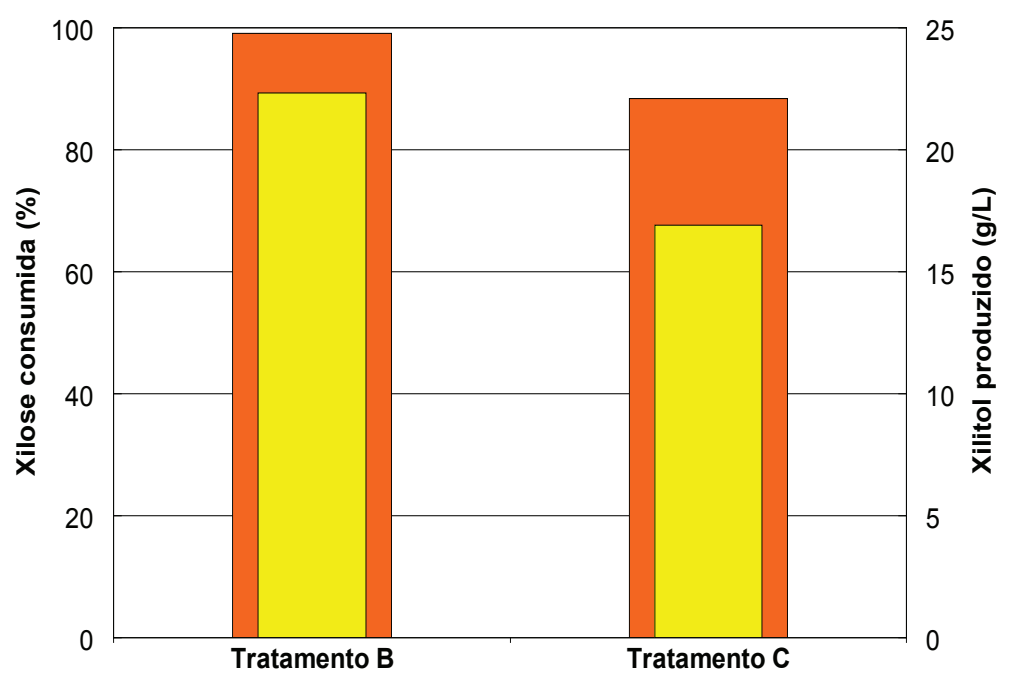

Figura 3: Consumo de xilose ( $\square$ ) e formação de xilitol ( $\square$ ) por C. guilliermondii após 66 horas de fermentação do hidrolisado hemicelulósico de bagaço de cana-de-açúcar submetido aos tratamentos pela alteração de $\mathrm{pH}$ combinado à adsorção em carvão vegetal ativado (B) e floculação por polímero vegetal (C).

O favorecimento da bioconversão de xilose em xilitol, em função do tipo de tratamento empregado, é confirmado pelos valores de rendimento e produtividade de xilitol apresentados na Figura 4. Semelhante ao ocorrido para remoção de fenóis, consumo de xilose e produção de xilitol, o tratamento do hidrolisado pela alteração de $\mathrm{pH}$ combinado à adsorção em carvão vegetal ativado (tratamento B) resultou em favorecimento destes parâmetros, sendo encontrado, nestas 
condições, o máximo valor de rendimento $\left(\mathrm{Y}_{\mathrm{P} / \mathrm{S}}=0,42 \mathrm{~g} / \mathrm{g}\right)$ e de produtividade volumétrica $\left(\mathrm{Q}_{\mathrm{P}}=0,34 \mathrm{~g} / \mathrm{L}\right.$.h $)$ de xilitol. Estes valores foram $8,8 \%$ e $24,0 \%$ respectivamente maiores em relação aos obtidos na fermentação em que o hidrolisado foi submetido à destoxificação com polímero vegetal (tratamento C). É evidenciado, ainda, a maior influência do tratamento sobre a produtividade de xilitol, o que pode ser explicado pelo efeito tóxico dos compostos sobre as membranas biológicas (PALMQVIST; HAHN-HÄGERDAL, 2000). De fato, as concentrações de fenóis, encontradas no presente trabalho, após as metodologias de destoxificação $(1,11$ e 2,62 $\mathrm{g} / \mathrm{L}$ ), são bem superiores à considerada inibitória a este bioprocesso, uma vez que a presença de somente $0,05 \mathrm{~g} / \mathrm{L}$ de fenóis no meio semi-sintético inibiu drasticamente a fermentabilidade do hidrolisado durante pesquisas com esta mesma levedura (FELIPE et al., 1999).

Marton et al. (2006), também, avaliaram o efeito da destoxificação do hidrolisado hemicelulósico de bagaço de cana pela alteração de $\mathrm{pH}$, combinada à adsorção em carvão vegetal ativado sobre a bioconversão de xilose em xilitol por C. guilliermondii. Segundo estes autores, esta metodologia resultou em $97 \%$ de remoção de fenóis, o que propiciou valores de rendimento $\left(Y_{P / S}=0,552 \mathrm{~g} / \mathrm{g}\right)$ e produtividade $\left(\mathrm{Q}_{\mathrm{P}}=0,465 \mathrm{~g} / \mathrm{L} . \mathrm{h}\right)$ de xilitol, valores estes superiores aos encontrados no presente trabalho.

Valores superiores de rendimento de xilitol foram constatados por Carvalho, Marton e Felipe (2005) durante pesquisas com hidrolisado de bagaço, tratado pela combinação de carvão vegetal ativado e resinas de troca iônica. Neste trabalho, o rendimento foi $0,89 \mathrm{~g} / \mathrm{g}$, o que correspondeu a um aumento de $53 \%$ em relação ao valor obtido no presente trabalho, por outro lado, a produtividade foi também muito baixa (0,39 g/L.h).

É importante considerar que as diferenças obtidas nessas pesquisas podem estar relacionadas não apenas aos distintos procedimentos de destoxificação empregados que propiciaram variações nos valores de remoção de fenóis, mas, ainda, à presença nesses hidrolisados de outros compostos tóxicos não avaliados no presente trabalho, os quais têm seus efeitos potencializados pela atuação sinérgica entre eles, além de variação nos teores de açúcares. 


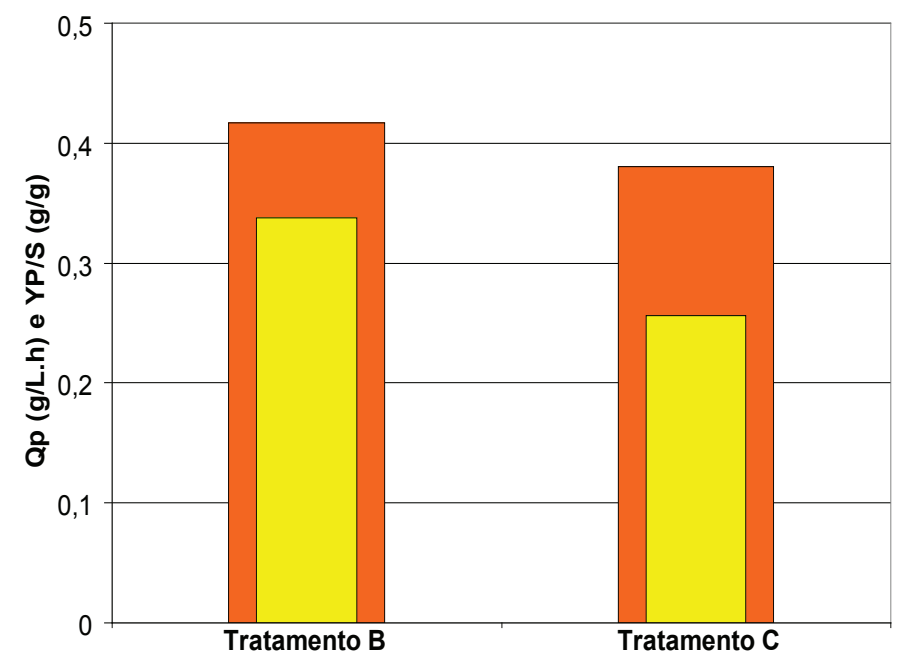

Figura 4: Rendimento ( $\square$ ) e produtividade volumétrica ( $\square$ ) de xilitol após 66 horas de fermentação por C. guilliermondii em hidrolisado hemicelulósico de bagaço de canade-açúcar submetido aos tratamentos pela alteração de $\mathrm{pH}$ combinado à adsorção em carvão vegetal ativado (B) e floculação por polímero vegetal (C).

\section{CONCLUSÃO}

Conclui-se que o tratamento do hidrolisado hemicelulósico de bagaço de cana, utilizando a combinação de ajuste de $\mathrm{pH}$ e adsorção em carvão vegetal ativado, foi mais eficiente para a remoção de fenóis totais com conseqüente favorecimento da bioconversão de xilose em xilitol por C. guilliermondii, em comparação ao tratamento em que se empregou o polímero vegetal. Além disto, ambos os tratamentos proporcionaram, apenas, pequena perda de xilose, enquanto a perda de glicose foi significativa. É importante mencionar que os baixos valores de rendimento e produtividade volumétrica de xilitol encontrados em ambas condições de destoxificação se devem a que, embora a concentração de fenóis, após o tratamento, fosse baixa, esta é ainda considerada inibitória a este bioprocesso. Ressalta-se ainda que o hidrolisado pode conter também ácido acético, íons metálicos, que são considerados inibitórios a este bioprocesso em função de suas concentrações no meio aliado, ao efeito sinérgico entre eles.

Em função de serem estes ensaios preliminares, e, considerando que a perda de xilose foi mínima para o tratamento com polímero, aliado ao fato da biodegradabilidade deste, além de seu baixo custo, pesquisas devem ser realizadas de forma a se estabelecer parâmetros do processo como concentração, temperatura e $\mathrm{pH}$ de atuação do polímero, avaliando-se também o efeito da destoxificação sobre outros compostos tóxicos presentes no hidrolisado.

\section{REFERÊNCIAS}

ABRABI 2005. Congresso e Exposição das Empresas de Biotecnologia, 6. Anais... São Paulo, p.13-15, set.2005. 
ACQUAQUÍMICA. Produtos, Acquapol ww. Disponível em: http://www.seta-sa.com.br/site/ acquaquimica/produto.php?codigo $=65$. Acesso em 01/2008a.

ACQUAQUÍMICA. Produtos, Bioclin. Disponível em: http://www.seta-sa.com.br/site/ acquaquimica/produto.php?codigo $=23$. Acesso em 01/2008b.

ALVES, L.A. et al Pretreatment of sugarcane bagasse hemicellulose hydrolysate for xylitol production by Candida guilliermondii. Applied Biochemistry and Biotechnology, v.70-72, p.89-98, 1998.

AMARTEY, S.; JEFRIES, T. An improvement in Pichia stipitis fermentation of acid-hydrolyzed hemicellulose achieved by overliming (calcium hydroxide treatment) and strain adaptation. World Journal of Microbiology and Biotechnology, v.12, p.281-283, 1996.

BICHO, P. A.; RUNNALS, P.L.; CUNNIGHAM, J.D.; LEE, H. Introduction of xylose reductase and xilitol dehydrogenase activities in Pachysolen tannophilus and Pichia stipitis on mixed sugars. Applied and Environmental Microbiology, v.54, n.1, p.50-54, 1988

CANILHA, L.; SILVA, J.B.A.; SOLENZAL, A.I.N. Eucalyptus hydrolysate detoxification with activated charcoal adsorption and ion-exchange resins for xylitol production. Process Biochemistry, v.39, p.1909-1912, 2004.

CARVALHO JUNIOR, R.; MARTON, J.M.; FELIPE, M.G.A. Avaliação do sistema combinado de tratamento do hidrolisado hemicelulósico de bagaço de cana-de-açúcar com carvão ativo e resinas de troca iônica para sua utilização como meio de fermentação. Revista Analytica, n.18, p.48-55, 2005.

CCC-CALORIE CONTROL COUNCIL. Reduced-calorie sweeteners: Xylitol. Disponível em: http://www.caloriecontrol.org/xylitol.html. Acesso em: 2 ago. 2007.

CONAB. Acompanhamento da Safra Brasileira Cana-de-Açúcar, Safra 2007/2008, terceiro levantamento, novembro/2007 - Companhia Nacional de Abastecimento. - Brasília: Conab, 2007. Disponível em: http://www.conab.gov.br/conabweb/download/safra/3lev-cana. pdf. Acesso em 01/2008.

FELIPE, M.G.A. Biotechnological Production of Xylitol from Lignocellulosic Materials. Lignocellulose Biodegradation, American Chemical Society, p.300-315, 2004.

FELIPE, M.G.A. et al. Effect of phenol concentration on the xylose-xylitol bioconversion by Candida guilliermondii. In: Symposium on Biotechnology for Fuels and Chemicals, 21., 1999, Fort Collins, Colorado. Program and Abstratets. Fort Collins, Colorado: University Park Holliday, 1999. Poster 2-22.

FELIPE, M.G.A. et al. Environmental parameters affecting xylitol production from sugar 
cane bagasse hemicellulosic hydrolysate by Candida guilliermondii. Journal of Industrial Microbiology \& Biotechnology, v.18, p.251-254,1997.

HYVÖNEN, L.; KOIVISTOINEN, P.; VOIROL, F. Food technological evaluation of xylitol. Advances in Food Research, v.28, p.373-403, 1982.

MANZ, U.; VANNINEN, E.; VOIROL, F. Xylitol - Its Properties and use as a sugar substitute in foods. In: Food Symposium On Sugar And Sugar Replacements, London, 10 Oct., 1973.

MARTINEZ, A. Estudo do processo de cristalização de xilitol obtido por via fermentativa. 2005. 175p. Tese (Doutorado em Biotecnologia Industrial) - Faculdade de Engenharia Química de Lorena, Lorena, 2005.

MARTINEZ, A. et al. Detoxification of dilute acid hydrolysates of lignocellulose with lime. Biotechnology Progress, v.17, p.287-293, 2001.

MARTON, J.M. et al. Evaluation of the activated charcoals and adsorption conditions used in the treatment of sugarcane bagasse hydrolysate for xylitol production. Brazilian Journal of Chemical Engineering, v.23, n.1, p.9-21, 2006.

MARTON, J. M. Avaliação de um sistema contínuo composto por colunas de carvão ativo e resinas de troca iônica para o tratamento do hidrolisado hemicelulósico de bagaço de cana-de-açúcar. 2005. 131p. Tese (Doutorato em Biotecnologia Industrial). Faculdade de Engenharia Química de Lorena, Lorena, 2005.

MARTON, J.M. Avaliação de diferentes carvões ativos e das condições de adsorção no tratamento do hidrolisado hemicelulósico de bagaço de cana para obtenção biotecnológica de xilitol. 2002. 105p. Dissertação (Mestrado em Biotecnologia Industrial) - Faculdade de Engenharia Química de Lorena, Lorena, 2002.

MATTILA, P.T.; KNUUTTILA, M.L.E.; SVANBERG, M.J. Dietary Xylitol Supplementation prevents osteoporotic changes in streptozotocin-diabetic rats. Metabolism Clinical and Experimental, v. 47, p. 578-583, 1998.

MELAJA, J.; HÄMÄLÄINEN, L. Process for Making Xylitol. US n.4.008.285. 15 fev. 1977.

PALMQVIST, E.; HAHN-HÄGERDAL, B. Fermentation of lignocellulosic hydrolysates II: Inhibitors and mechanisms of inhibition. Bioresource Technology, v.74, p.25-33, 2000.

PEPPER, T.; OLINGER, P.M. Xylitol in Sugar - Free Confections. Food Technology, v.42, n.10, 1988.

ROBERTO, I. C.; MUSSATTO, S.; RODRIGUES, R.C.L.B. Dilute-acid hydrolysis for optimization of xylose recovery from rice straw in a semi-pilot reactor. Industrial Crops and Products, v. 17, p. 171-176, 2003.

Nucleus, v. 5. n. 1, abr. 2008 
ROBERTO, I.C. et al. Utilization of sugar cane bagasse hemicellulosic hydrolyzate by Candida guilliermondii for xilitol production. Bioresource Technology, v.36, p.271-275, 1991.

RODRIGUES, R.C.L.B. et al. Enhanced xykitol production by precultivation of Candida guilliermondii cells in sugarcane bagasse hemicellulosic. Current Microbiology, v.53, p.5359, 2006.

RODRIGUES, R.C.L.B. et al. The influence of $\mathrm{pH}$, temnperature and hydrolysate concentration on the removal of volatile and nonvolatile compounds from sugarcane bagasse hemicellulosic hydrolisate treated with activated charcoal before or after vacuum evaporation. Brazialian Journal of Chemical Engineering, v.18, p.299-311, 2001.

ROSA, S.M.A. et al. Xylose reductase production by Candida guilliermondii. Applied Biochemistry and Biotechnology, v.70-72, p.127-135, 1998.

SANTANA, J.; SOUZA, S.O. Subprodutos da cana-de-açúcar. Informe agropecuário, v.10, p.22-26, 1984.

SHEN, P. et al. Remineralization of enamel subsurface lesions by sugar-free chewing gum containing casein phosphopepticle-amorphous calcium phosphate. Journal of Dental Research, v.80, n.12, p.2066-2070, 2001.

SILVA, D.D.V.; FELIPE, M.G.A. Effect of glucose:xylose ratio on xylose reductase and xylitol dehydrogenase activities from Candida guilliermondii in sugarcane bagasse hydrolysate. Journal of Chemical Technology and Biotechnology, v.81, p.1294-1300, 2006.

SILVA, S.S.; MATOS, Z.R.; CARVALHO, W. Effects of sulfuric acid loading and residence time on the composition of sugarcane bagasse hydrolysate and its use as a source of xilose for xylitol bioproduction. Biotechnology progress, v.21, p.1449-1452, 2005.

SILVA, T.F.M. et al. Xylitol production by Candida guilliermondii from sugarcane bagasse hydrolysate treated with polymer of vegetable origin. In: VI Brazilian Meeting on Chemistry of Food and Beverages. Book of Abstracts, p.153, 2006.

SILVA, T.F.M. Avaliação de polímeros de origem vegetal no tratamento de hidrolisado de bagaço de cana-de-açucar para obtenção de xilitol. 2006. 90p. Dissertação (Mestrado em Biotecnologia Industrial) - Escola de Engenharia de Lorena, Lorena, 2006.

SINGLETON, V.L.; ORTHOFER, R.; LAMUELA-RAVENTÓS, R.M.Analysis of total phenols and other oxidation substrates and antioxidants by means of Folin-Ciocalteu reagent. Methods in Enzymology, v.299, p.152-179, 1999.

SUGAI, J.K.; DELGENES, J.P. Catabolic repression of induction of aldose reductase activity and utilization of mixed hemicellulosic sugars in Candida guilliermondii. Current Microbiology, v.31, p.239-244, 1995. 
VIÑALS, M.V. Aplicação de resinas de troca iônica no tratamento de hidrolisado hemicelulósico para processos fermentativos. 2001. 75p. Dissertação (Mestrado em Biotecnologia Industrial) - Faculdade de Engenharia Química de Lorena, Lorena, 2001.

WATSON, N.E. et al. Factors in acid treated bagasse inhibiting ethanol production from D-xylose by Pachysolen tannophilus. Enzyme and Microbial Technology, v.6, p.451-456, 1984.

ZABNER, J. et al. The osmolyte reduces the salt concentration of airway surface liquid and may enhance bacterial killing. Proceedings of the National Academy of Sciences of the USA, v.97, n.21, p.11614-11619, 2000. 